\title{
Modeling the influence of foreign investments on food security based on panel cointegration models
}

\section{Elena D. Kopnova}

Associate Professor, Department of Statistics and Data Analysis National Research University Higher School of Economics Address: 20, Myasnitskaya Street, Moscow, 101000, Russian Federation E-mail:ekopnova@hse.ru

\section{Lilia A. Rodionova}

Associate Professor, Department of Statistics and Data Analysis National Research University Higher School of Economics Address: 20, Myasnitskaya Street, Moscow, 101000, Russian Federation E-mail: Irodionova@hse.ru

\section{Abstract}

The paper studies the problems of food security as the basis for the stability of the country's economic development. Despite the economic growth of most countries in the world, the problems of hunger continue to be acute in developing countries. This undermines the food security of these countries and can pose a threat to world peace as a whole. Numerous studies show that foreign investment plays an important role in the creation of food security, but this effect is ambiguous. The most common methods of analysis in recent researches are descriptive analysis and panel data models.

In this article, our approach to analyzing the impact of foreign investment is based on panel cointegration models; the interpretation of the results uses the impulse response function based on an error correction model. Countries of North Africa are considered as an example of the implementation of this approach. Data from the World Bank and the Food and Agriculture Organization for 1991-2014 for seven countries (Algeria, Egypt, Libya, Morocco, Sudan, Tunisia, Western Sahara) were selected for analysis. In this paper, we have also tested the methodology for selecting the food security indicator based on analysis of the matrix of cointegration relations.

The results show that foreign investment has a significant long-term impact on food security, but in the short term no effect was detected. The proposed modeling methodology can be extended to any region of the world to monitor and evaluate the effectiveness of the current economic policy to combat hunger and poverty.

Key words: modeling of economic systems, panel cointegration, food security, foreign investment, Pedroni panel tests, panel tests of unit root.

Citation: Kopnova E.D., Rodionova L.A. (2017) Modeling the influence of foreign investments on food security based on panel cointegration models. Business Informatics, no. 3 (41), pp. 20-29. DOI: $10.17323 / 1998-0663.2017 .3 .20 .29$. 


\section{Introduction}

$\mathrm{O}$ ne of the important goals of humanity is sustainable development of society. This is difficult to imagine without progress in the eradication of hunger and malnutrition [1]. Despite the fact that enough food is produced in the world to feed everyone, the Food and Agriculture Organization (FAO) estimates that in 2015 about 792.5 million people continued to suffer from chronic hunger ${ }^{1}$. The vast majority of the hungry lived in developing countries. According to the FAO, food security is defined by the conditions "when all people, at all times, have physical, social and economic access to sufficient, safe and nutritious food that meets their dietary needs and food preferences for an active and healthy life" [2]. Today, food security is not only one of the basic human needs and basic human rights, but it plays an important role in a country's economic development and the preservation of world peace [3]. International organizations under FAO auspices have adopted an agreement on ensuring food security in developing countries to achieve Zero Hunger by 2030. Investments in agricultural development amounting on average to US\$265 billion a year are one of the necessary measures [4]. Such investment flows require constant monitoring of the situation and the evaluation of possible risks and the effectiveness of the policy based on thorough consideration of general long-term indicators for food security and socio-economic development. Thus, the need to monitor the current situation of food security in developing countries, the development of a methodology for monitoring economic policy and obtaining quantitative estimates of the longterm effects of investment determine the relevance of the selected topic of this study. Note that the preliminary results of this study were published in the series of "Economics" preprints of the National Research University Higher School of Economics [5].

\section{The impact of investment on food security: the theoretical background}

In the literature on food security, different concepts to explain the determinants of food security are highlighted: modernization, economic dependency, urban bias, neo-Malthusian population pressure, ecological evolutionary processes and militarism among others [6]. Let us dwell on some of them.

In modernization theory internal sources of economic development play an important role. Domestic investment and the development of education are a reliable basis for industrialization and the cultural transformation of society, which leads to economic growth and the creation of stronger institutions that, in turn, contribute to improving the overall welfare of the population. Investing in human capital and increasing the level of education creates a workforce with modern motivation, skills and a high degree of adaptation to modern technologies, which is an important component of economic growth [7]. International trade and investment stimulate economic development, promote the spread of new technologies and methods, and improve social security. Foreign studies also show that economic development, industrialization, education and urbanization can improve the quality of life of the population, and economic growth has a positive effect on the food supply in the country and life expectancy in general. According to modernization theory, international capital flows and technology contribute to economic growth, increase the incomes of all population groups and, as a result, reduce the risks of hunger in the country $[8,9]$. In the theory

\footnotetext{
${ }^{1}$ Statistical data are available at FAO website: http://faostat3.fao.org/ download/I/IC/E
} 
of modernization, an important role in the formation of food security is also assigned to political institutions. Strong political institutions, and the democratization of society, contributes to economic and social development, inhibits corruption, encourages the growth of public investment in nutrition, education and health, provides political stability, improves the quality of life, all of which significantly affects food security [10].

In economic dependency theory, international trade and foreign investment have a negative impact on social security. Studies have shown that export dependence reduces economic growth and the quality of life, cuts total food supply, and contributes to child mortality [11]. Foreign direct investment (FDI) has a negative impact on food security for several reasons. Multinational corporations repatriate most of their profits and prevent the formation of domestic firms, which leads to a reduction of domestic economic growth. Foreign investment is largely focused on advanced technology and the creation of a smaller number of jobs, although highly paid. From this come inequality of income and poverty. Foreign investment is mainly concentrated in export industries and has weak links with the internal market, which also has a negative impact on domestic production. In the short term, FDI can create economic growth, but the long-term effects of the penetration of foreign capital are negative [12].

These concepts of food security are reflected in the research related to Africa [13]. Study of the FDI effect in African countries shows that countries with well-developed financial markets benefit significantly, and the problem of excessive dependence of the economy on FDI exists. In our study, the effect of FDI will be evaluated by the example of the countries of North Africa, where some progress has already been achieved in the field of combating hunger.

\section{Review of existing methods for modeling food security factors}

In the last decade, problems of food security have been actively explored and significant results have been obtained, especially by the FAO. Only in a few works, however, is panel data analysis used as an econometric tool for the full sample of developing countries $[9,12$, 14]. In most works, the authors confine themselves to descriptive data analysis. If regional comparisons are carried out, for example, in African countries in conditions of limited sampling, and modeling methods using panel time series are used, then a number of problems in estimating models with fixed and random effects arise $[15,16]$. Nonstationarity of time-series is one such problem. In our work, we will try to develop a methodology for modeling the determinants of food security based on panel cointegration [17]. This methodology makes it possible to take into account the problems of nonstationarity in modeling the determinants of food security using panel time series. This approach will be described in more detail in the "Proposed research methodology" section.

\section{Problems of measuring food security}

For a comprehensive assessment of food security in countries around the world since 1996, the FAO uses a set of 30 indicators $^{2}$ covering various aspects of the problem and classifying food security into four dimensions - availability, access, utilization, stability. The indicators of availability describe the value of food production and productivity, level of stocks, adequacy of average dietary energy supply, etc. Access

\footnotetext{
${ }^{2}$ A list of all food safety indicators, definitions and detailed calculation methodology are available on the FAO website: http://www.fao.org/economic/ess/ess-fs/ess-fadata/en/\#.V2Qip-pv7IV
} 
covers the economic opportunity to purchase food and transport it (percent of paved roads over total roads, road density, GDP per capita, etc.). Utilization evaluates food consumption in terms of nutritional standards for calories, protein and trace elements. Stability characterizes the situation with the adequacy of food in the country in different periods (cereal import dependency ratio, domestic food price volatility, etc.).

Such a wide range of indicators is necessary in order to assess food security in various aspects. Food security is not just enough food. For example, despite the declining share of hungry people in Africa and the problem of the lack of energy value of nutrition, a number of problems related to the quality of the diet remain. In sub-Saharan Africa, the phenomenon of "hidden hunger" is observed when, due to lack or inadequate intake of nutrients, various manifestations of malnutrition (anemia among pregnant women and children under 5 years of age, vitamin A deficiency, children under 5 years of age who are underweight, etc.) arise.

Note that empirical studies on food security use different indicators to measure food security. Among all the ones proposed, it can distinguish the average energy value of the diet, the percentage of newborns weighing less than 2500 grams at birth, the proportion of foods consumed containing starch [19], daily protein intake $[6,12]$, the proportion of undernourished [14], etc. It can be concluded that among researchers there is no single opinion and substantive justification for answering the question which of the 30 indicators should be chosen as a measure of food security. In our study, we propose a methodology for selecting a food security indicator based on an analysis of the matrix of cointegration links, described in the "Proposed research methodology" section.

\section{Information base of the research}

The countries of North Africa were considered as an example of the implementation of the proposed methodology. Data from the $\mathrm{FAO}^{3}$ and the World Bank ${ }^{4}$ for seven countries of North Africa (Algeria, Egypt, Libya, Morocco, Sudan, Tunisia, Western Sahara) covering the period 1991-2014 were used in the work. For analysis of the food security of the countries, a number of indicators were chosen that characterize the considered problem from different angles: food security indicators, characteristics of economic development and resources, international trade indicators, indicators of investment in agriculture and indicators of the financial system. A more detailed description of variables, descriptive statistics of indicators are given in the pre-print [5]. Note that the problem of skipping data for some indicators and countries (especially for Western Sahara and Sudan) exists.

The change over time of some indicators that characterize food security in the countries studied in different aspects is presented in Figure 1. The amount of food consumed, expressed by average dietary energy supply adequacy, exceeds $100 \%$ of the daily ration. This suggests that the population of North Africa is on average not starving. The prevalence of anemia among pregnant women, indicating the quality of food consumed, declined significantly during the study period and was less than $35 \%$ for the countries under consideration after 2011. It should be noted that a rather large variation of cereal import dependency ratio exists (which has a negative impact on food security): Libya (more than 90\%) demonstrates the highest figures, Egypt is the lowest (less than 40\%). In general, a positive trend is observed both in quantity and as a diet of the population. This shows that measures to improve food security

\footnotetext{
${ }^{3}$ http://faostat3.fao.org/download/I/IC/E

${ }^{4} \mathrm{http}: / /$ data.worldbank.org/indicator
} 
A)

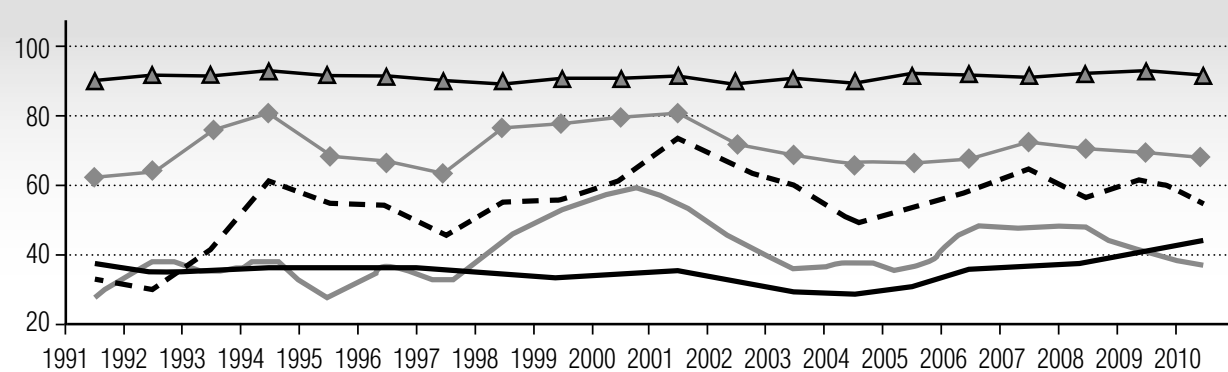

$\longrightarrow$ Algeria $\longrightarrow$ Egypt $\longrightarrow$ Morocco $\quad-\quad-$ Tunisia $\rightarrow$ Libya

B)

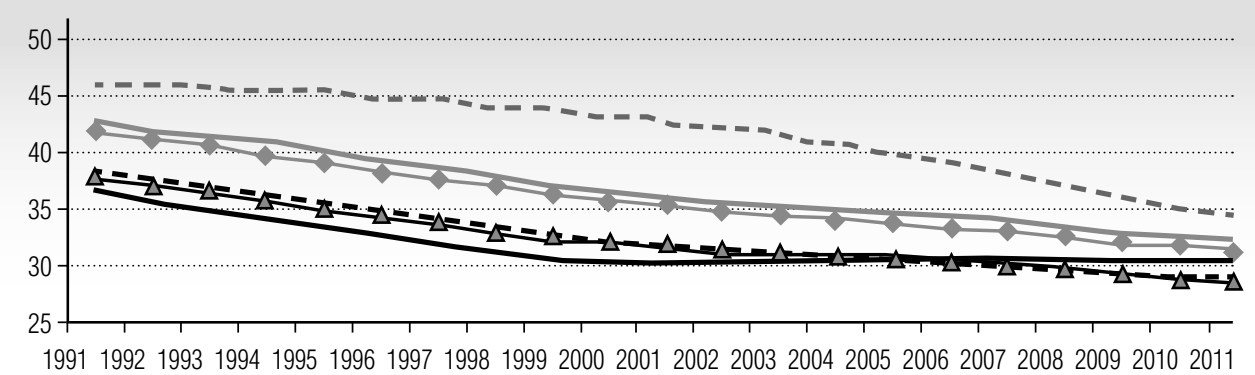

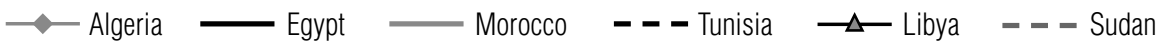

C)

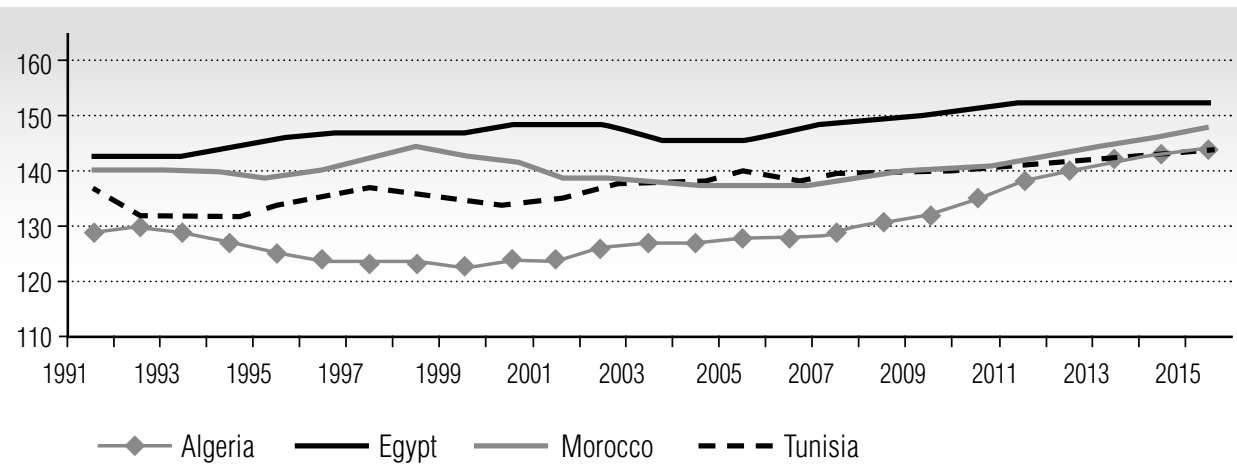

Fig. 1. Evolution of some food security indicators (calculated based on FAO statistical data)
A) Cereal import dependency ratio, \%
B) Prevalence of anemia among pregnant women, \%
C) Average Dietary Energy Supply Adequacy, \%

in the countries of North Africa are effective and this experience is useful for study.

\section{Proposed research methodology}

The specificity of the available data for Africa (a lot of omissions, a limited sample of countries for the selected region, nonstationarity of time series) do not allow us to evaluate the clas- sical panel data models. In this paper, to test the theoretical assumptions about the effect of foreign investment, we will use an approach based on panel cointegration [17] and implemented in this study in several stages.

Stage 1. Stationarity of processes. To study the long-term relationships between the indicators being analyzed, it is first necessary to check the time series for stationarity, taking 
into account the panel structure of the data. For each of the indicators, panel unit-root tests were carried out at $10 \%$ significance level. We considered five tests: the Levin-Lin-Chu unit-root test (LLC), the Breitung unit-root test, the Im-Pesaran-Shin unit-root test (IPS), Fisher-type unit-root tests based on augmented Dickey-Fuller tests (ADF-Fisher) and based on Phillips-Perron tests (PP-Fisher), all three modifications (with a constant, trend, constant and trend) $[16,19,20]$. All tests have as the null hypothesis that all the panels contain a unit root. The results of testing for one of the characteristics of food security - cereal import dependency ratio (CIDR) in the countries of North Africa are given as an example. The statistics and the corresponding probabilities ( $\mathrm{P}$-value) are given in Table $1^{5}$.

These results allow us to conclude that the CIDR is the realization of a nonstationary process, integrated of the first order (I(1)). A similar testing approach was used for the other 40 indicators of the social, economic and financial spheres of countries. Among the characteristics of food security, 10 out of 30 indicators also turned out to be a realization of $\mathrm{I}(1)$ and were taken for further analysis. These results also indicate that the processes (different aspects of food security, economic characteristics and foreign investment) are in development, which should contribute to progress in improving the lives of the poor. Nonstationarity of processes is also necessary for further research of long-term relationships between indicators.

Stage 2. Panel cointegration test. To further analyze long-term relationships, it is necessary to determine the cointegration of processes. For time series that were a realization of I(1), Pedroni cointegration tests were applied [21]. Seven different tests with a null hypothesis of no cointegration in non-stationary panels were performed. Test statistics were grouped into two categories: group-mean statistics that average the results of individual country test statistics and panel statistics that pool the statistics along the within-dimension [15]. In Table 2, the results of the Pedroni cointegration tests for CIDR and FDI (inflow) are given: the test statistics and their corresponding probabilities (P-value). The null hypothesis of no cointegration is rejected at $10 \%$ significance level. The decision about the cointegration of processes was accepted if the hypothesis was rejected for 3 or more statistics out of 7 .

Panel unit-root tests

Table 1.

for cereal import dependency ratio (CIDR)

\begin{tabular}{c|c|c|c|c|c}
\multicolumn{2}{c|}{ Indicators } & \multicolumn{2}{c}{ CIDR } & \multicolumn{2}{c}{$\Delta$ CIDR } \\
\hline \multirow{2}{*}{ Type of statistics } & Test & Statistics & P-value & Statistics & P-value \\
\hline \multirow{2}{*}{ Panel statistics } & LLC & -1.02 & 0.16 & -3.02 & 0.001 \\
\hline \multirow{3}{*}{ Group-mean statistics } & IPS & -2.94 & 0.002 & -5.17 & 0.000 \\
\cline { 2 - 6 } & ADF-Fisher & 24.71 & 0.006 & 44.08 & 0.000 \\
\cline { 2 - 6 } & PP-Fisher & 18.47 & 0.048 & 45.06 & 0.000 \\
\hline
\end{tabular}

\footnotetext{
${ }^{5}$ The decision about the stationarity was accepted, if the hypothesis of a unit root was rejected at $10 \%$ level for all modifications for three or more statistics. For conflicting testing results, priority was given to group average statistics in favor of the reliability of the conclusion
} 
Pedroni cointegration tests for cereal import

dependency ratio (CIDR) and inflow of FDI

\begin{tabular}{l|c|c|c}
\hline \multicolumn{2}{c|}{ Variables } & \multicolumn{2}{c}{ CIDR and FDI } \\
\hline \multirow{2}{*}{ Test statistics } & Statistics & P-value \\
\hline \multirow{4}{*}{ Panel statistics } & v-St & 2.08 & 0.02 \\
\cline { 2 - 4 } & rho-St & -1.31 & 0.09 \\
\cline { 2 - 4 } & PP-St & -2.17 & 0.02 \\
\cline { 2 - 4 } & ADF-St & -3.13 & 0.001 \\
\hline \multirow{3}{*}{ Group-mean statistics } & rho-St & -0.14 & 0.44 \\
\cline { 2 - 4 } & PP-St & -1.36 & 0.08 \\
\cline { 2 - 4 } & ADF-St & -1.61 & 0.05 \\
\hline
\end{tabular}

Based on the test results, it can be concluded that the CIDR and FDI processes analyzed are cointegrated and further analysis of long-term relationships is possible for them.

Stage 3. Selecting a food security indicator. Based on Pedroni cointegration tests, the cointegration relationships between the other indicators were analyzed. Based on analysis of the test statistics, the matrix of cointegration links was compiled in which the maximum number of statistics indicating cases of rejection of the null hypothesis of no cointegration at the $10 \%$ significance level is given [5]. The calculations so obtained made it possible to reveal the distribution of mutual influences of the indicators analyzed and to determine those of them that accumulate the greatest number of connections and can be used as integral indicators in further analysis. The indicator that accumulates the largest number of links can be viewed as a proxy of food security. Cereal import dependency ratio (CIDR) was selected as such a characteristic in our study. It has 33 links to other indicators from 40 analyzed. Access to improved water sources also accumulates a large number of cointegration links (31 out of 40 ).
Stage 4. The long-run relationships. The expected long-term relations were analyzed for cointegrated variables. Each cointegrating relation contained three endogenous variables and a constant.

$$
y_{1 i t}=\alpha_{i}+\beta_{1} y_{2 i t}+\beta_{2} y_{3 i t}+\varepsilon_{i t},
$$

where $y_{1 i t}, y_{2 i t}, y_{3 i t}-$ the values of the indicators for country $i$ in year $t$

$\varepsilon_{i t}$ - the error of cointegration;

$\alpha_{i}-$ coefficients corresponding to individual effects;

$\beta_{k}-$ components of cointegrated vectors.

Multivariate cointegration was also tested by the Fisher-Johansen test.

The evaluation of the parameters for cointegrating equations was carried out using Dynamic Ordinary Least Squares with automatic selection of the auxiliary lags number of $y_{1 i t}$ applying Schwarz criterion. Standard errors were calculated using the New-West formula adjusted for heteroscedasticity and autocorrelation. The estimation results of equation (1) for CIDR and FDI (inflow and outflow) are presented in Table 3. Analysis of the regression residuals of the model (1) was carried out using 
panel unit root tests, which indicate about cointegration between the investigated variables and the suitability of the model.

Stage 5. The short-run relationships. To estimate the short-term relationships, error correction model based on panel data was used in the form of the equation:

$$
\begin{gathered}
\Delta y_{1 i t}=\alpha_{i}^{(\Delta)}+\beta_{1}^{(\Delta)} \Delta y_{1 i t-1}+\beta_{2}^{(\Delta)} \Delta y_{2 i t-1}+ \\
+\beta_{3}^{(\Delta)} y_{3 i t-1}+\delta_{1}^{(\Delta)} E C M_{i t-1}+\varepsilon_{i t}^{(\Delta)}
\end{gathered}
$$

where $\Delta y_{j i t}=y_{j i t}-y_{j i t-1} \quad j=1,2,3 \quad-$ increments of the related indicators;

$\alpha_{i}^{(\Delta)}-$ coefficients characterizing the individual effects;

$E C M_{i t-1}$ - the adjustment mechanism equilibrium, which are the residuals of the cointegrating equations (1);

$\delta_{1}^{(\Delta)}-$ coefficient which characterizes the recovery rate of the equilibrium state for $y_{1 i t}$;

$\beta_{k}^{(\Delta)}-$ regression coefficients;

$\varepsilon_{i t}^{(\Delta)}-$ regression error.

An estimation of the short-term relation parameters was carried out according to a method of Panel Least Squares, followed by residuals diagnostics. The residuals of the model were checked for autocorrelation with the Wooldridge test for serial correlation in panel data. The estimation results of the model (2) are also given in Table 3.

Note that the coefficient at ECM, characterizing the correction to long-term equilibrium, is significant at the level of 0.01 and has the correct sign. It shows that the correction of CIDR in its deviation from the equilibrium trajectory with potentially possible short-term shocks occurs about a year and two months later (1/0.7059).

\section{Results and prospects of the study}

Estimation results of the models (1)-(2) and significant estimates of model parameters confirm the expected long-term and short-term relationships. At 5\% significance level we can assume that there is a direct long-term relationship between CIDR and FDI inflows. The relationship between CIDR and FDI outflow was not detected. With the increase in FDI inflows in the country, CIDR increases in the long

The results of evaluation of long- and short-term relation

\begin{tabular}{|c|c|c|c|}
\hline \multicolumn{2}{|c|}{ Cointegrating equation (1) } & \multicolumn{2}{|c|}{ Error correction model (2) } \\
\hline Variable & Coefficient & Variable & Coefficient \\
\hline \multirow{2}{*}{ FDI inflows, FDI } & \multirow{2}{*}{$0.004^{* *}$} & $\Delta \mathrm{CIDR}(\mathrm{t}-1)$ & $0.2902^{2 * * x}$ \\
\hline & & $\Delta \mathrm{FDI}(\mathrm{t}-1)$ & 0.0005 \\
\hline \multirow{2}{*}{ FDI outflows, FDO } & \multirow{2}{*}{-0.001} & $\Delta \mathrm{FDO}(\mathrm{t}-1)$ & 0.0001 \\
\hline & & ECM(t-1) & $-0.7059^{* * *}$ \\
\hline \multicolumn{2}{|c|}{$\mathrm{N}=87 ; \mathrm{R}^{2}=0.96 ; \mathrm{DW}=1.741^{\#} ;$ J-B-test $\chi^{2}=0.144^{\#}$} & \multicolumn{2}{|c|}{$\mathrm{N}=87 ; \mathrm{R}^{2}=0.28 ; \mathrm{DW}=1.81 ;$ J-B-test $\chi^{2}=0.21$} \\
\hline $\begin{array}{l}\text { ** Indicate the } \\
\star * \star \\
\text { \# Indicate th } \\
\text { \#\# Indicate the } \\
\text { \# }\end{array}$ & $\begin{array}{l}\text { nificant at } 5 \% \text { (p } \\
\text { gnificant at } 1 \% \text { (p } \\
\text {-Watson statistic } \\
\text { e-Bera statistics }\end{array}$ & $\begin{array}{l}\text { model residu } \\
\text { model residua }\end{array}$ & utocorrelation. \\
\hline
\end{tabular}
between CIDR and FDI 
term. This effect can be regarded as negative, as food security deteriorates and theoretical backgrounds for the concept of economic dependence are confirmed. The long-term elasticity coefficient was 0.088 . So, an increase in FDI by $1 \%$ is accompanied by an increase in CIDR of $0.088 \%$. Speaking of short-term effects, the results show that the effect of FDI in the short term are not significant (model (2)).

The significant and positive estimate at the lags of the absolute growth of $\Delta \operatorname{CIDR}(t-1)$ in equations (2) indicates the inertial variability of CIDR and this should be taken into account in forecasting. This fact, in addition to a low coefficient of determination in error correction model $\left(R^{2}=0.28\right)$, points to the need for further analysis in identifying the factors of CIDR dynamics.

Based on the estimates of model parameters for the food security indicator impulse response functions were calculated (Figure 2). This allows an assessment of the impact of a single error change (shock) at a rate of one standard deviation and characterizes the mechanisms of short-term adjustments to the equilibrium state.

CIDR initially increases in response to shocks of FDI inflows, but after 4 years there is a loss of reaction (to zero). After 5-6 years an indicator reduction is observed which in the context of food security is a positive effect because it slightly decreases CIDR. The opposite reaction is observed in response to shocks of FDI outflows. In this case, the CIDR increases gradually in 6-7 years by an average of $1.6 \%$ and then remains at the new, higher level. These results confirm the long duration of the analysed processes. The detection of the

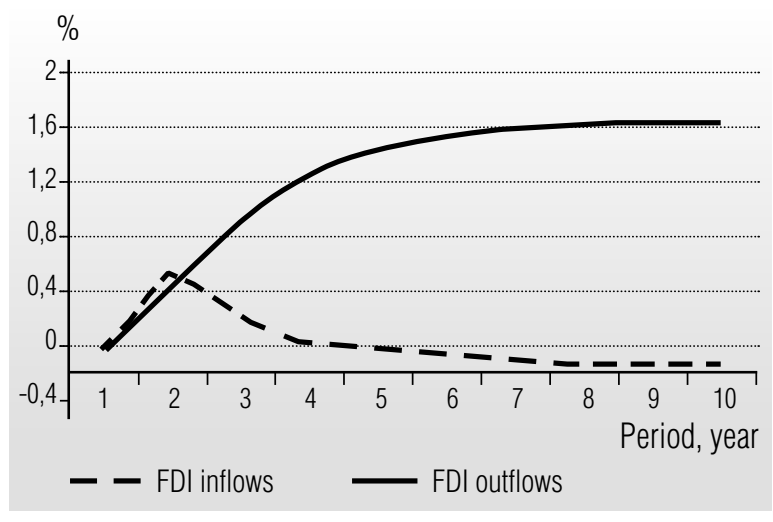

Fig. 2. Responses of CIDR on the impulse FDI

long-term effects of FDI indicates that investments will only be seen as significant over the long term. This fact also points to the necessity of improving the investment policy and to raise the role of domestic assets.

\section{Conclusion}

The proposed approach for a justified choice of the food security indicator based on the matrix of cointegration links, the method of estimating the effect of foreign investment based panel cointegration model and the calculation of impulse response functions, provides an opportunity to quantify the effect of foreign investment on food security in the long term. It is impossible to expect instant effects in the modeling of such complex socio-economic processes as food security. This study can also contribute to the development of a methodology for monitoring economic policies in African countries. It will create conditions for food security, taking into account long-term financing indicators, and thus have some value in light of the formulated millennium goals to achieve Zero Hunger.

\section{References}

1. FAO (2015) FAO and the 17 sustainable development goals, 2015. Available at: http://www.fao.org/3/ a-i4997e.pdf (accessed 20 March 2017).

2. FAO (2015) The state of food insecurity in the world, 2015. Available at: http://www.fao.org/3/a-i4646e/ index.html (accessed 20 March 2017). 
3. Jenkins J.C., Scanlan S.J., Peterson L. (2007) Military famine, human rights, and child hunger: A cross-national analysis, 1990-2000. Journal of Conflict Resolution, vol. 51, no. 6, pp. 823-847.

4. FAO (2015) Achieving zero hunger: The critical role of investments in social protection and agriculture, 2015. Available at: http://www.fao.org/publications/card/ru/c/91014696-3723-4df5-b729-2b4e55b22e8f/ (accessed 20 March 2017).

5. Kopnova E., Rodionova L. (2017) An analysis of the economic determinants of food security in North Africa. Moscow: HSE. Series WP BRP “Basic research program”, no. 166/EC/2017.

6. Jenkins J.C., Scanlan S.J. (2001) Food security in less developed countries, 1970-1990. American Sociological Review, no. 66, pp. 718-744.

7. Barro R.J. (1991) Economic growth in a cross section of countries. Quarterly Journal of Economics, no. 106 , pp. 407-443.

8. Firebaugh G., Beck F. (1994) Does growth benefit the masses? Growth, dependence, and welfare in the Third World. American Sociological Review, no. 59, pp. 631-653.

9. Scanlan S.J. (2004) Women, food security, and development in less-industrialized societies: Contributions and challenges for the new century. World Development, no. 32. pp. 1807-1829.

10. Safaei J. (2006) Is democracy good for health? International Journal of Health Services, no. 36, pp. 767-786.

11. Wickrama K.A., Mulford C.L. (1996) Political democracy, economic development, disarticulation, and social well-being in developing countries. The Sociological Quarterly, no. 37, pp. 375-390.

12. Mihalache-O'Keef A., Li Q. (2011) Modernization vs. dependency revisited: Effects of foreign direct investment on food security in less developed countries. International Studies Quarterly, vol. 55, no. 1, pp. 71-93.

13. Skoet J., Stamoulis K., Deuss A. (2004) Investing in agriculture for growth and food security in the ACP countries. WP No. 04-22 FAO - ESA.

14. Austin K.F., McKinney L.A. (2012) Disease, war, hunger, and deprivation: A cross-national investigation of the determinants of life expectancy in less-developed and sub-Saharan African nations. Sociological Perspectives, no. 55, pp. 421-447.

15. Phillips P.C.B., Moon H.R. (2000) Nonstationary panel data analysis: An overview of some recent developments. Econometric Reviews, no. 19, pp. 263-286.

16. Im K.S., Pesaran M.H., Shin Y. (2003) Testing for unit roots in heterogeneous panels. Journal of Econometrics, no. 115, pp. 53-74.

17. Hamilton J.D. (1994) Time series analysis. Princeton: Princeton University Press.

18. Poleman T.D. (1997) Recent trends in food availability and nutritional wellbeing. Population and Environment, no. 19, pp. 145-165.

19. Breitung J., Das S. (2005) Panel unit root tests under cross-sectional dependence. Statistica Neerlandica, no. 59 , pp. 414-433.

20. Choi I. (2001) Unit root tests for panel data. Journal of International Money and Finance, no. 20, pp. 249272.

21. Pedroni P. (2004) Panel cointegration: Asymptotic and finite sample properties of pooled time series tests with an application to the PPP hypothesis. Econometric Theory, no. 20, pp. 597-625. 